\title{
ЭКОНОМИЧЕСКИЙ РОСТ И АГРАРНЫЙ СЕКТОР СССР (1955-1985). НОВЫЙ МЕТОДОЛОГИЧЕСКИЙ ПОДХОД'
}

\section{ECONOMIC GROWTH AND THE AGRICULTURAL SECTOR OF THE USSR (1955-1985). NEW METHODOLOGICAL APPROACH}

G. Popov

Summary: The economic history of the USSR remains a field of scientific discussion now. However, there is no generally accepted concept of the causes of the economic crisis of the Soviet economy that led to the collapse of the USSR. In this regard, the author offers a new methodological approach that shows the dependence of the dynamics of the USSR's GDP on the growth of agricultural production. The author relies on statistical indicators of grain production in the USSR in the 1950s-first half of the 1980s. The aim of the article is to develop a new methodological approach to determining the nature of the impact of agricultural production on the USSR's GDP. The author concludes that after 1953 agriculture continued to strongly influence the growth of the USSR's GDP.

Keywords: Soviet economy, planned economy, economic development of the USSR, agricultural development of the USSR.
Попов Григорий Германович

к.э.н., с.н.С., Российская академия народного хозяйства и государственной службы при Президенте Российской Федерации GGPopov2009@mail.ru

Аннотация: В настоящее время экономическая история СССР остается полем научных дискуссий. Тем не менее, нет общепризнанной концепции причин экономического кризиса советской экономики, приведшего к распаду СССР. В этой связи автор предлагает новый методологический подход, показывающий зависимость динамики ВВП СССР от роста производства аграрной продукции. Автор опирается на статистические показатели производства зерна в СССР в 1950-е - первой половине 1980-х гг. Цель статьи заключается в выработке нового методологического подхода к определению характера влияния производства сельскохозяйственной продукции на ВВП СССР. Автор приходит к выводу, что после 1953 г. сельское хозяйство продолжало сильно влиять на прирост ВВП СССР.

Ключевые слова: советская экономика, плановая экономика, экономическое развитие СССР, аграрное развитие СССР.

мального развития, вызванным кризисом капитализма в эпоху мировых войн.

В период Холодной войны и незадолго после нее на Западе доказывалась отсталость советской модели плановой экономики на базе анализа системы национальных счетов. Однако некоторые современные исследователи ставят под сомнение данный методологический подход к определению эффективности плановых экономик, поскольку качественные характеристики производившихся в них товаров сильно отличались от западных стандартов, что не позволяет верно вычислить курсовые разницы. Однако отказ от системы национальных счетов как инструмента сравнительного анализа плановых и рыночных экономик лишает исследователей удобной платформы для анализа социально-экономического развития Советского Союза. Как определить - был ли эффективен советский строй или нет? Можно применить такие критерии, как продолжительность жизни, потребление калорий и т.п., однако они позволят нам определить различия в благосостоянии обществ, но оно определяется мике [15, с. 2-4]. Для либеральной экономической мысли в целом советский период остается отклонением от нор- 
не только политическим строем, но и внешними факторами.

Вопрос о том, как институциональные изменения трансформируются в экономические показатели, например, в ВВП, интересует исследователей давно, но относительно анализа советской экономики продвижение в этом смысле не столь значительное. Недавно на базе новых подходов к оценке системы национальных счетов советской экономики был сделан вывод, что СССР не столь сильно отставал от Запада, как считалось долгое время. Но возникает вопрос, за счет чего шло столь успешное догоняющее развитие, и было ли тому причиной наличие сильного репрессивного аппарата? В некоторых работах мы поднимали вопрос о роли марксистской идеологии и коммунистического режима на развитие России в прошлом веке. Однако мы это делали без использования ВВП как инструмента анализа. Правда, в одной из работ мы применили сравнение национальных доходов поздней Российской империи и СССР периода НЭПа, и в итоге нами было установлено, что экономическая политика советской власти вплоть до 1930 г. была менее эффективной, нежели политика имперского правительства, но причиной тому была потеря квалифицированных кадров в Первую мировую и Гражданскую войны, что повысило стоимость труда в период НЭПа на фоне наличия избыточного предложения рабочих рук (в основном неквалифицированной рабочей силы).

В настоящей работе мы берем для анализа период 1955-1985 гг. После смерти Сталина в СССР начались реформы, направленные на либерализацию хозяйственных отношений, в первую очередь это касалось отношений села и государства. Результаты этих преобразований, которые ассоциируются с фигурой Г.М. Маленкова, стали в полной мере ощущаться не ранее рубежа 19541955 гг., тогда же советская экономика столкнулась с проблемой разбалансировки между производством и потреблением, правда, эта проблема не была столь ощутимой, но все-таки потребовала в 1961 г. проведения денежной реформы, сопровождавшейся повышением цен на товары массового потребления. В этой связи отправной хронологически точной анализа нами выбраны реформы Г.М. Маленкова, которые можно условно назвать первой попыткой построения социализма с человеческим лицом. Но эти реформы сопровождались развитием идеи создания в СССР сильной технократии, которая должна была вывести страну из признанного властью кризиса, который выражался в первую очередь в отставании СССР от ведущих стран капиталистического мира. Технократический курс в постсталинском СССР в итоге взял верх над концепцией Г.М. Маленкова, что в итоге привело к сворачиванию его реформ.

В 1985 г. начинается смена курса развития Советского государства в сторону либерализации и внедрения ры- ночных отношений в экономике, поэтому мы берем 1985 г. как условную веху в развитии СССР. В этом году происходит не только смена власти в Кремле, но и переход советской экономики к последнему в своей истории и не имевшему по масштабам аналогов в Советском государстве ранее росту, который быстро перешел в стадию циклического кризиса, ознаменовавшему конец «перестройки». Но, главное, к 1985 г. советская правящая элита начинает сильно сомневаться в верности выбранного после 1955 г. курса развития и в эффективности технократии, в связи с чем новая власть в Кремле попыталась внести существенные изменения в саму марксистско-ленинскую идеологию.

Было ли тридцатилетие 1955-1985 гг. триумфом России, или же, как это представляли на Западе в годы Холодной войны либералы, это был ошибочный путь, чреватый регрессом и падением страны в пропасть? Мы предполагаем, что избранный в середине 1950-х гг. курс соответствовал вызовам, с которыми столкнулось советское общество. Главными из них были дефицит продовольствия и энергии, ставшие одной из причин кризиса советского общества и распада СССР. В этой связи нашей целью является показать, насколько меры по развитию сельского хозяйства повлияли на рост ВВП, начиная с середины 1950-х до «перестройки», при этом мы предлагаем свой оригинальный методологический подход. Базовым (нормативным) выступает ВВП 1954 г. (в этом году реформы Г.М. Маленкова стали давать ощутимые результаты, начинается заметный уход от сталинской модели экономики). Разумеется, на ВВП оказывали влияние и другие факторы, например, качество управления народным хозяйством, однако именно выпуск продовольственной продукции стал центральным фактором роста.

Относительно низкие показатели роста производства продовольствия в конце 1940-х - начале 1950-х гг. были, помимо последствий Великой Отечественной войны и других причин, результатом излишней централизации, поэтому увеличение объема продукции аграрного сектора в постсталинский период демонстрирует более высокое качество управления народным хозяйством. В соответствии с поставленной целью определены следующие задачи:

1. дать характеристику аграрному развитию в СССР;

2. показать логическую взаимосвязь между ростом ВВП и сельского хозяйства СССР, определив при этом критический минимальный показатель производства продукции, выраженный в ц/га;

3. вывести индекс влияния производства сельскохозяйственной продукции на ВВП, используя логическое моделирование.

В соответствии с поставленными задачами, в работе применены методы экстраполяции, логического моде- 
лирования и компаративистского анализа. В своей работе А.А. Афанасьева и О.С. Пономарева отражены основные новейшие достижения российской эконометрики в вопросе применения теоремы Кобба-Дугласа в ее модифицированных вариантах к анализу советской / российской экономики. Однако эти авторы предложили оригинальные идеи, требующие развития и, на наш взгляд, развития, они умножают модифицированную функцию Кобба-Дугласа на коэффициент структурного фактора [3, с. 25]. А.А. Афанасьев и О.С. Пономарев ассоциируют инфраструктурный фактор It (1990) со среднегодовой стоимостью основных фондов отраслей транспорта и связи в сопоставимых ценах 1990 г., что, на наш взгляд, достаточно упрощенно, так как не принимаются во внимание ЖKX, финансовые учреждения и т.д. Но в рассуждениях А.А. Афанасьева и О.С. Пономарева мы находим другой более важный, с точки зрения методологии применения эконометрики к историко-экономическому анализу, аспект - они умножают модифицированную функцию Кобба-Дугласа на инфраструктурный фактор, таким образом указывая, что внешние факторы одновременно могут влиять как на труд, так и на капитал, и на общую производительность. В целом, мы согласны с подобным подходом.

Мы следуем примеру А.А. Афанасьева и О.С. Пономарева, которые пошли по пути детализации факторов, влияющих на экономический рост. Они также допустили влияние экстернальных факторов на эндогенные факторы, учтя затраты на инфраструктуру (эти затраты во многом обусловлены общественным выбором), чего мы не видим во многих других российских моделях экономического роста, построенных на базе формулы КоббаДугласа $[17,20]$. В России авторы обычно работают с этой формулой, не учитывая последствия общественного выбора, создающих экстерналии, однако модели экономического роста строятся уже для заданного хозяйственного порядка без объяснения, каким образом этот порядок влияет на распределение ВВП.

Нас интересует эффект от стимулирования роста производства сельскохозяйственной продукции, выражаемый в приросте ВВП (ниже мы обозначаем его как коэффициент FS). Сама производственная функция в формате настоящего исследования нас не интересует, поскольку мы не ставим задачу установить, как изменения объемов и пропорций труда и капитала влияли на ВВП, нам нужны внешние эффекты, созданные государственной экономической политикой. Поэтому мы просто умножаем базовый (1954 г.) ВВП на выведенный нами коэффициент FS. Аргументом в пользу нашего вывода о ведущей роли аграрной политики государства в советский период служат данные по производительности труда ГУЛАГа, заключенные которого, обеспечивались продовольствием по самому минимуму. В 1941 г. руководством ГУЛАГа было определено, что лагерный заключенный дает примерно
50\% от выработки свободного гражданина [4, с. 191; 5]. В СССР, как и в любой развитой индустриальной стране, 75-80\% экономического роста обеспечивалось за повышения производительности труда, что во многом зависело от качества и калорийности питания работников. Это, в свою очередь, требовало от правительства дополнительных усилий по интенсификации земледелия и скотоводства.

Увеличение продуктивности сельского хозяйства позволяло высвобождать из аграрного сектора рабочие руки, которые использовались в первую очередь в строительстве жилья и легкой промышленности. В одной из работ российских авторов сделан вывод, что рост производительности труда в мировой экономике имеет сильную корреляционную зависимость от роста потребления. Эти расчеты сделаны для периода с 1980 по 2010 гг. Поскольку в выборке присутствуют совершенно разные по емкости экономики и численности населения страны, то можно утверждать, что рост производительности труда зависит, в первую очередь, от изменений в потреблении. Б.Л. Лавровский и его коллеги определяют величину потребления в долларах США, и в их анализе отсутствует СССР / Россия [10]. Проведение анализа в международных сопоставлениях зависимости производительности труда от потребления для России сложно, так как определение курса рубля к доллару даже для 1980-х гг. остается достаточно спорным вопросом [9, с. 19-20]. В особой степени это относится к периоду 19401950-х гг.

Государство влияло на потребление в первую очередь стимулированием сельского хозяйства, эффективность этих мероприятий мы оцениваем в центнерах зерновых на гектар, так как зерновые до сих остаются определяющим фактором в потреблении калорий. Чем выше производительность земледелия, тем больше ресурсов правительство может направить в животноводство и другие сегменты аграрного сектора, что подтверждается для советской экономики данными, приведенными у Т.Г. Нефедовой [14, с. 30]. Обозначим среднегодовую урожайность зерновых как od, этот коэффициент мы будем исчислять в ц/га. Среднегодовой показатель урожайности для периода 1938-1940-е гг. составлял 7,7 ц/га. В США урожайность зерновых достигла 10 ц/га в 1950 г., когда американцы еще не испытывали недостатка продовольствия. Мы считаем, что 10 ц/га есть оптимальный показатель для индустриальных обществ 1920-1950-х гг., тогда 10 ц/га как FS = 1,0, средняя для 1954-1958 гг. урожайность зерновых должна дать значение $\mathrm{FS}=0,9$ (округленный от 9,1 ц/га исторически достоверный средний показатель).

Рост производства сельскохозяйственной продукции стал ощущаться, по данным И.Г. Калабекова, в конце 1950-х гг. Ранее сельское хозяйство СССР по своей 
продуктивности оставалось на уровне 1940 г. даже в начале 1950-х гг. после сильнейшего в истории XX в. кризиса периода Великой Отечественной войны. В период «оттепели» прогресс оказался незначительным, в середине 1960-х гг. урожайность находилась на уровне чуть выше 10 ц / га. [9, с. 71]. В 1975 г. начался спад в производительности советского зерноводства, который продолжался до 1985 г., что не могло не ослабить эффект от роста продуктивности советского сельского хозяйства в 1965-1975 гг. К тому же, прирост урожайности зерновых был по 0,5 ц/га в год, что и обусловило медленный прирост потребления продовольствия. Этим и объясняется на фоне начавшегося спада в 1975 г. сбора зерновых не столь быстрое возрастание добавленной стоимости в промышленности в \% от ВВП после 1970 г. [9, с. 33]. Поэтому можно утверждать, что в 1965-1975 гг. сельское хозяйство СССР достигло оптимума, когда урожайность составляла около 13-15 ц/га (FS = 1,3-1,5).

Очевидно, что 13 ц/га урожайности зерновых стало в 1985 г. критическим показателем, после чего советское руководство срочно начало принимать меры для подъема сельского хозяйства, всерьез задумавшись о либеральных реформах на селе. Поэтому FS = 1,3 есть для периода «заката» советской эпохи некая нижняя критическая планка, поэтому наш вывод о том, что FS = 1,5 есть оптимальное значение для поддержания работы советской экономики в нормальном состоянии верен. В 1990 г. урожайность зерновых в РСФСР стала максимальной за весь советский период - около 17 ц/га, но сделано это было за счет особо крупных затрат.

Структурируем наши рассуждения в таблице 1, где мы показываем алгоритм связи производства с потреблением. При этом мы опираемся на данные по ВВП, приводимые у М. Харрисона, который отталкивается от расчетов А. Меддисона. Мы не считаем их точными, но приблизительную тенденцию динамики советского ВВП они отражают.

Таблица 1 Среднедушевой ВВП и индекс роста производства зерновых в СССР $[14,18,21]$

\begin{tabular}{|l|l|l|l|l|}
\hline Период & $1949-1955$ & $1955-1969$ & $1970-1983$ & $1983-1985$ \\
\hline $\begin{array}{l}\text { Среднегодовой ВВП } \\
\text { на душу населения } \\
\text { в международных } \\
\text { долларах США 1990 г. } \\
\text { (от минимального в } \\
\text { начале периода зна- } \\
\text { чения до наивысшего } \\
\text { в конце периода, } \\
\text { приблизительная } \\
\text { оценка) }\end{array}$ & $\begin{array}{l}3300- \\
6300\end{array}$ & $\begin{array}{l}6400- \\
7100\end{array}$ & $\begin{array}{l}7200- \\
7800\end{array}$ \\
\hline Значение FS & $0,7-0,9$ & $0,9-1,2$ & $1,3-1,5$ & $1,3-1,7$ \\
\hline
\end{tabular}

Как следует из данных, указанных в таблице 1, рост советского сельского хозяйства пришелся в основном на период, так называемого, «застоя», тогда же наблюдается и серьезный прирост среднедушевого ВВП. Рост советской экономики в 1955-1969 гг. был менее зависим от производства аграрной продукции, что очевидно даже без применения метода корреляции, но то же самое нельзя сказать о периоде 1949-1955 гг., когда сталинская модель управления экономикой и сельским хозяйством исчерпала себя к началу 1950-х гг. Рост экономики СССР при урожайности зерновых менее 10 ц/га был незначительным.

Советское сельское хозяйство едва ли могло долго держать планку производительности выше 15 ц/га, поэтому FS = 1,5 обеспечивало около 7100 долларов на душу населения (ВВП по М. Харрисону и А. Меддисону в международных долларах 1990 г.). Принимая во внимание, что численность населения СССР в 1979 г. составила 262 миллиона человек, то общий объем ВВП в долларах 1990 г. должен был составить около 1,8 трл долларов. В пределах этого показателя советский ВВП колебался в конце 1970-х - начале 1980-х гг. Представим, что население СССР в середине 1950-х гг. составляло бы 262 млн чел., в таком случае приблизительный объем ВВП составил бы около 839 млрд долларов (международных 1990 г.). Таким образом, с конца 1970-х гг. советская экономика имела долю ВВП в размере почти 1 трл. международных долларов 1990 г. как результат долгосрочных мер в сельском хозяйстве.

Мы можем сформулировать наш вывод об эффекте аграрной политики Советского государства следующим образом. Округлим 839 млрд долларов ВВП СССР до 840 млрд. При неизменности численности населения или при его незначительном росте такой ВВП имел бы СССР, если бы не произошли серьезные сдвиги в сельском хозяйстве. Но большой рост населения при неизменности производительности аграрного сектора только вел бы к сокращению среднедушевого ВВП либо его незначительному приросту, то есть, система оставалась бы неизменной на протяжении жизни целого поколения, будучи обреченной на очередной «голодомор». Таким образом, 840 млрд долларов есть некая константа, обозначающая стартовый ВВП СССР, ее мы можем представить в виде коэффициента bGDP $=840$. Но тогда достигнутый в конце 1970-х гг. ВВП в почти 1,84 трл долларов можно назвать некоей второй константой (hGDP = 1840), выше которой советский аграрный сектор уже не мог обеспечить должного уровня снабжения городов продовольствием без кардинальных реформ, которые сопровождались в реальности сокращением землеемкости сельского хозяйства уже России и других бывших союзных республик.

В связи с этим, реформы Г.М. Маленкова и Н.С. Хрущева, а также аграрные преобразования в эпоху 
Л.И. Брежнева выглядят в ином свете. Это были меры, обеспечившие серьезный прорыв экономики. Но к концу советского периода государственная поддержка сельского хозяйства составляла $81 \%$ от суммы валовой выручки, что было очень много даже по критериям плановой экономики. Правда, в условиях рынка российское зерновое хозяйство сделало немалые успехи, подняв урожайность с 13,5 ц/га до 21 ц/га в период 2000-2010 гг., однако это произошло уже в несколько иных технологических условиях на фоне сокращения землеемкости сельского хозяйства. Относительно низкая, по сравнению с постсоветским периодом, эффективность сельскохозяйственных предприятий в СССР отчасти объяснима тем, что на них лежали социальные функции, например, строительство жилых домов и содержание дорог, на что шли в среднем 25\% их инвестиций. Вместе с тем, площадь посевных площадей, поголовья скота и прочие количественные показатели были выше в советский период, нежели в постсоветский, поэтому наша оценка эффективности советской политики в 1955-1985 гг. в аграрной сфере в целом верна. Следует отметить, что, в отличии от сталинского периода, акцент после 1955 г. делался на интенсивном росте сельского хозяйства, однако и экстенсивные методы тоже не полностью исключались $[14$, с. 29, 30].

Главным фактором роста производства в сельском хозяйстве СССР в 1955-1985 гг. оставалось увеличение землеемкости, что было характерно и для сталинского периода. Сложившийся в СССР технологический уклад не давал для Советского государства большого поля для маневра в вопросе изменения характера сельскохозяйственного производства и, соответственно, обеспечения роста экономики в целом. Разбалансировка между потреблением и производством, если судить только по ситуации в сельском хозяйстве в конце 1970-х - первой половине 1980-х гг., не могла наступить только в силу дефицита производства зерновых и других основных видов аграрной продукции. Очевидно, что проблема дефицита продовольствия в СССР стала следствием иных обстоятельств.

\section{ЛИТЕРАТУРА}

1. Альпидовская М.Л., Вахрушева Н.А., Корняков В.И. Уроки истории: экономический подъем в послевоенные годы (1945-1960) // Энергия: экономика, техника, экология. 2017. № 5. С. 42-48.

2. Андреенков С.Н. «Целинный проект» 1954 г. в аграрной истории Сибири и Казахстана // Гуманитарные науки в Сибири. 2017. № 24 (2). С. $103-108$.

3. Афанасьев А.А., Пономарев 0.С. Производственная функция народного хозяйства России в 1990-2012 гг. // Экономика и математические методы. 2014. T. 5. № 4. C. 21-33.

4. Барнс А.С. Принудительный труд в советском тылу: ГУЛАГ военного времени // Советский тыл 1941-1945: повседневная жизнь в годы войны / Сост. Физелер Б., Марквик Р.Д. М.: Политическая энциклопедия, 2019. 383 с.

5. Бородкин Л.И. Именем Сталина. Гулаг на «Великих стройках коммунизма» (интервью). Эхо Москвы. 2010. Режим доступа: https://echo.msk.ru/programs/ staliname/657435-echo/\#element-text (Дата обращения 17.10.2020).

6. Вальцев С.В. Эпоха развитого социализма как время упущенных возможностей // Проблемы современной науки и образования. 2012. № 4. С. 4-22.

7. Вальцев С.В. Оценка преобразований, проводимых в СССР под руководством Н.С. Хрущева // Проблемы современной науки и образования. 2012. C. $10-20$.

8. Винслав Ю.Б. Советская оборонная промышленность: из предвоенной, военной и послевоенной истории организации и управления // Российский экономический журнал. 2017. № 4. С. 23-35.

9. Калабеков И.Г. СССР и страны мира в цифрах. Справочное издание. М.: Русаки, 2015. 239 с.

10. Лавровский Б.Л., Позднякова И.В., Федоров А.А., Спиридонова Е.В. Производительность труда и уровень потребления: межстрановые сопоставления (эмпирический анализ) // Мир экономики и управления. 2016. Т. 16. № 2. С. 5-15.

11. Латов Ю.В., Нуреев Р.М. «Косыгинские» реформы в контексте советских политико-экономических циклов // Историко-экономические исследования. 2016. T. 17. № 3. С. $488-504$.

12. Логвенков И.С. Демонтаж СССР: историография причин, условий и факторов // Вестник Московского университета. Серия 21: Управление (государство и общество). 2017. № 4. С. 129-145.

13. Некрасов В.Л. Советский экономический реформизм эпохи Н.С. Хрущева: авторитарный реформатор, партийно-государственная система и академическое общество // Новый исторический вестник. 2017. № 4. С. 72-73.

14. Нефедова Т.Г. Трансформация сельского хозяйства России: мифология и реальность // Мир России. 2013. № 1. С. 29-60.

15. Попов Г.Г. Между либерализацией коммунизма и ортодоксальным марксизмом (осмысление эволюции советского экономического развития 19501960-х гг.) // Terra Economicus. 2019. 17 (4). С. 113-128.

16. Сагателян Г.Ш., Дядя С.А. Кризис советской системы мотивации труда в 30-80-е годы XX века // Вестник Рязанского государственного университета им. С.А. Есенина. 2017. № 2 (55). С. 45-56.

17. Сериков С.Г. Выявление специфики общественного воспроизводства Амурской области с помощью производственной функции Кобба - Дугласа // Вестник университета. 2019. № 12. С. 144-153. 
18. Сидоров А.В. От кризиса к распаду: СССР в 1990-1991 гг. // Вестник Московского университета. Серия 21: Управление (государство и общество). 2016. № 1. C. 66-101.

19. Синицын Р.В. 0 достоверности дореволюционной статистики в контексте оценки урожайности зерновых культур статистическими органами Российской империи и СССР // Новые исторические перспективы: от Балтики до Тихого океана. 2017. № 2-3. С. 23-33.

20. Суворов Н.В., Ахунов Р.Р., Губарев Р.В., Дзюба Е.И., Файзуллин Ф.С. Применение производственной функции Кобба-Дугласа для анализа промышленного комплекса региона // Экономика региона. 2020. Т. 16. Вып. 1. С. 187-200.

21. Harrison M. The Soviet economy. 1917-1991: Its life and afterlife. 2017. Режим доступа: https://voxeu.org/article/soviet-economy-1917-1991-its-life-andafterlife (Дата обращения 17.10.2020).

22. Smirnov S. Economic Fluctuations in Russia (from the late 1920 s to 2015) // Rus ᄀsian Journal of Economics. 2015. № 1 (2). P. 130-153.

23. Voskoboynikov I. Sources of long run economic growth of the Russian economy before and after the global financial crisis // NRU Higher School of Economics. Series: WP BRP «Economics». 2017. No. 179. P. 348-365.

(c) Попов Григорий Германович (GGPopov2009@mail.ru).

Журнал «Современная наука: актуальные проблемы теории и практики»

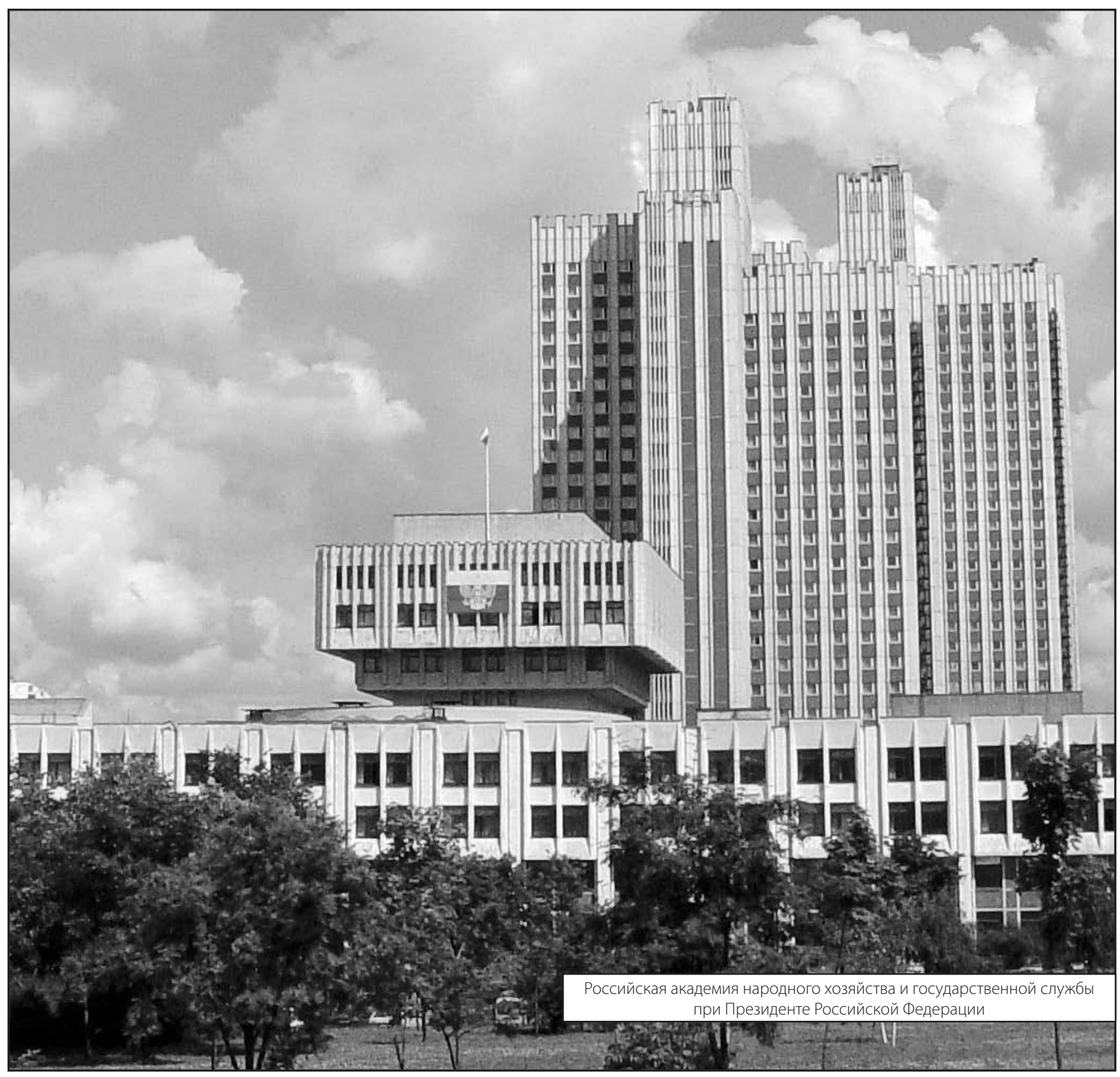

